\title{
A developmental stage- and Kidins220/ARMS-dependent switch in astrocyte responsiveness to brain-derived neurotrophic factor
}

Fanny Jaudon $^{1 \$ \uparrow}$, Martina Albini ${ }^{1,2 \$}$, Stefano Ferroni $^{3}$, Fabio Benfenati ${ }^{1,4}$ and Fabrizia Cesca ${ }^{1,5 *}$

${ }^{1}$ Center for Synaptic Neuroscience and Technology, Istituto Italiano di Tecnologia, 16132 Genova, Italy

${ }^{2}$ Department of Experimental Medicine, University of Genova, 16132 Genova, Italy

${ }^{3}$ Department of Pharmacy and Biotechnology, University of Bologna, 40126 Bologna, Italy

${ }^{4}$ IRCCS Ospedale Policlinico San Martino, Genova, Italy

${ }^{5}$ Department of Life Sciences, University of Trieste, 34127 Trieste, Italy

\$ equal contribution

† Present address: Department of Life Sciences, University of Trieste, 34127 Trieste, Italy

*To whom correspondence should be addressed:

Fabrizia Cesca

Department of Life Sciences, University of Trieste

Via L. Giorgieri, 5 - 34127 Trieste, Italy

Phone: +39 040-558-8727

e-mail: fcesca@units.it

Running title: Kidins220 and BDNF-TrkB signaling in astrocytes 


\begin{abstract}
Astroglial cells are key to maintain nervous system homeostasis, as they are able to perceive a wide variety of extracellular signals and to transduce them into responses that may be protective or disruptive toward neighboring neurons through the activation of distinct signaling pathways. Neurotrophins are a family of growth factors known for their pleiotropic effects on neuronal survival, maturation and plasticity. In this work, we investigated: (i) the signaling competence of embryonic and postnatal primary cortical astrocytes exposed to brain-derived neurotrophic factor (BDNF); and (ii) the role of the scaffold protein Kinase D interacting substrate/ankyrin repeat-rich membrane spanning (Kidins220/ARMS), a transmembrane protein that mediates neurotrophin signaling in neurons, in the astrocyte response to BDNF. We found a shift from a kinase-based response in embryonic cells to a predominantly $\left[\mathrm{Ca}^{2+}\right]_{i}$-based response in postnatal cultures associated with the decreased expression of the full-length BDNF receptor TrkB. We also found that Kidins220/ARMS contributes to the BDNF-activated intracellular signaling in astrocytes by potentiating both kinase and $\left[\mathrm{Ca}^{2+}\right]_{\mathrm{i}}$ pathways. Finally, Kidins220/ARMS contributes to astrocytes' homeostatic function by controlling the expression of the inwardly rectifying potassium channel (Kir) 4.1. Overall, our data contribute to the understanding of the complex role played by astrocytes within the central nervous system and identify Kidins220/ARMS as a novel actor in the increasing number of pathologies characterized by astrocytes' dysfunctions.
\end{abstract}




\section{INTRODUCTION}

Astroglia, the most abundant cell population of the central nervous system (CNS), is taking the stage in the neuroscience field because of its multifaceted role in the modulation of neural physiology at increasing levels of complexity, from the single synapse to higher circuits (1). Key to astrocyte performances is the capability to sense a wide range of extracellular signals and consequently activate intracellular signaling pathways, which can be kinase-based, as for the ubiquitous mitogen-activated protein kinase (MAPK) (SHP2/Ras/ERK), signal transducer and activator of transcription (STAT) 1/3 and nuclear factor $\kappa \mathrm{B}(\mathrm{NF \kappa B})$ cascades (2), or initiated via second messengers that trigger the release of $\mathrm{Ca}^{2+}$ ions from the endoplasmic reticulum (3). Intracellular $\mathrm{Ca}^{2+}$ transients $\left(\left[\mathrm{Ca}^{2+}\right]_{\mathrm{i}}\right)$ underlie the vast majority of astrocytes' responses by mediating the release of a plethora of soluble factors globally referred to as gliotransmitters, which include neurotransmitters, trophic factors, hormones, cytokines and several other bio-active molecules. Gliotransmitters exert both autocrine and paracrine functions, thus controlling and coordinating the activity of astroglia itself and of neighboring neurons (4).

While the mechanisms underlying astrocyte uptake/release of glutamate, ATP and other gliotransmitters, as well as the ability to respond to neurotransmitters such as glutamate, are well described and agreed upon by the scientific community, to what extent astrocytes produce, sense and respond to neurotrophins, such as nerve-growth factor (NGF) and brain-derived neurotrophic factor (BDNF), is still object of debate. Neurotrophins are mostly studied for their pleiotropic effects on neurons, as they control virtually every aspect of neuronal physiology, including maturation, axonal and dendritic differentiation, synaptogenesis and various forms of synaptic plasticity (5). Besides their well-known effects on neurons, however, neurotrophins also modulate important aspects of astrocyte physiology (6). Within the CNS, the most abundant neurotrophin is BDNF, which signals through its tropomyosin-related kinase B full-length (TrkB) and truncated (TrkB-T1) receptors (5). Astrocytes predominantly express the truncated form of the BDNF receptor, which triggers release of $\mathrm{Ca}^{2+}$ from intracellular stores (7) and activates various kinase pathways $(8,9)$ independently of the full-length protein. The BDNF/TkB-T1 system modulates several astrocyte properties, such as astrocyte morphological maturation and their capability of sensing neurotransmission by controlling 
the membrane targeting of glycine and GABA transporters (9-12). An aberrant activation of this pathway has been described in the experimental autoimmune encephalomyelitis rodent model for multiple sclerosis, where overexpressed TrkB-T1 induces neuronal death by promoting the release of nitric oxide (13). Moreover, astrocytic TrkB-T1 contributes to neuropathic pain and neurological dysfunctions in rodent models of spinal cord injury and of amyotrophic lateral sclerosis $(14,15)$. TrkB-T1 is arguably the predominant receptor isoform expressed in astrocytes, however some reports indicated that cultured astrocytes can also express full-length $\operatorname{TrkB}(16,17)$. Interestingly, some evidence indicates that TrkB expression by astrocytes occurs upon CNS injury or in the presence of chronic and inflammatory diseases, such as multiple sclerosis (18-20). Importantly, the competence of astrocytes to perceive and respond to BDNF seems to be different in various brain areas (21), thus adding a further layer of complexity to the system. Besides sensing extracellular BDNF through specific receptors, astrocytes also uptake and recycle proBDNF and BDNF in vitro and in vivo (22, 23). An increasing body of evidence suggests that cultured astrocytes produce and secrete BDNF under basal conditions $(24,25)$, and that BDNF expression is increased by specific stimuli (26-30).

Although the contribution of astrocytes to neuronal function is becoming clear, the cellular and molecular mechanisms underlying the regulation of astrocyte-neuron communication mediated by neurotrophins remains incompletely understood. Kinase D interacting substrate/ankyrin repeatrich membrane spanning (Kidins220/ARMS, henceforth referred to as Kidins220) is one of the several proteins involved in the neurotrophin pathways. Kidins 220 is a four-pass transmembrane protein enriched in the nervous system, where it is expressed by both neurons and astrocytes and is involved in various aspects of neuronal differentiation and plasticity $(31,32)$. Recently, we have shown that Kidins220 participates to the molecular events inducing spontaneous and evoked $\left[\mathrm{Ca}^{2+}\right]_{\mathrm{i}}$ transients in primary astrocytes, controlling the vulnerability of astrocytes to genotoxic stress and the maturation of co-cultured neurons (33).

In this work, we have investigated the responsivity of astrocytes to BDNF and the role played by Kidins220 in astrocytic BDNF signaling. We first compared the signaling competence of embryonic and postnatal primary cortical astrocytes exposed to BDNF and found a developmental shift from a kinase-based response in embryonic cells to a predominantly $\left[\mathrm{Ca}^{2+}\right]_{\mathrm{i}}$-based response in 
postnatal cultures, which was paralleled by the reduced expression of full-length TrkB. Second, we addressed the role of Kidins220 in BDNF-induced signaling in astrocytes, and showed that Kidins220 significantly contributes to both kinase and $\left[\mathrm{Ca}^{2+}\right]_{\mathrm{i}}$ pathways. The data contribute to the understanding of the complex response of astrocytes to neurotrophins, describing a developmental stage- and Kidins220-dependent switch in astrocyte responsiveness to BDNF. 


\section{RESULTS}

BDNF induces the activation of intracellular signaling pathways mediated by full-length TrkB and Kidins220 in embryonic astrocytes

To determine the role of Kidins 220 in the modulation of BDNF signaling in astrocytes, the expression of TrkB was compared by western blot analysis in wild type and Kidins $220^{-/-}$primary astrocytes derived from E18.5 embryos at 15 days in vitro (DIV), a stage at which cultures have reached confluence. Kidins $220^{-/-}$astrocytes displayed a significant reduction of both full length and truncated forms of TrkB of around $40 \%$ and $50 \%$ respectively, compared to wild type cells, while the ratio between these two isoforms remained unchanged (Fig. 1A). We then compared the expression level of the main downstream effectors of the BDNF/TrkB pathway, such as mitogen-activated protein kinase (MAPK)1/2, phospholipase $\mathrm{C} \gamma(\mathrm{PLC} \gamma)$ and Akt. Whereas total protein levels of MAPK1/2 and Akt were unaffected, we found a significant reduction of PLC $\gamma$ in Kidins $220^{-/-}$ astrocytes (Fig. 1B). We then asked whether Kidins220 ablation in these cells affects the response to BDNF and TrkB-mediated signaling. Fifteen DIV astrocytes were treated with $50 \mathrm{ng} / \mathrm{ml}$ BDNF for 5 or $30 \mathrm{~min}$ and the phosphorylation levels of MAPK1/2, PLC $\gamma$ and Akt were quantified by western blot with phospho-specific antibodies (Fig. 1C). While the basal phosphorylation levels of MAPK1/2 and Akt were unchanged in Kidins $220^{--}$astrocytes, we observed a reduction in their activation upon BDNF stimulation that reached statistical significance for MAPK1/2. We also detected a significant reduction of the basal phosphorylation level of PLC $\gamma$, while the percent increase in PLC $\gamma$ phosphorylation induced by the BDNF was similar in wild type and Kidins $220^{-/}$astrocytes. A similar trend was observed when lower concentrations of BDNF $(1 \mathrm{ng} / \mathrm{ml})$ were used; in this case, however, the fold change increase in MAPK phosphorylation was reduced compared to that observed with 50 ng/ml BDNF (Suppl. Fig. 1). Of note, we could not detect reliable phosphorylation of PLC $\gamma$ under these experimental conditions (not shown). While astrocytes predominantly express the truncated form of TrkB, some reports indicate that primary astrocytes can also express full-length neurotrophin receptors under physiological conditions and/or upon specific stimuli $(17,34,35)$. Although, under 
our culturing conditions, primary glial cultures are predominantly represented by astrocytes with only a small percentage of microglial cells (33), we wanted to confirm that the observed activation of signaling pathways was ascribable to astrocytes. Thus, we performed immunostaining experiments using anti-phospho TrkB (Tyr516, the phosphorylation site required for MAPK activation) and antiGFAP antibodies. Indeed, stimulation with BDNF increased pTrkB fluorescence intensity in GFAPpositive cells, confirming that full length TrkB activation occurred in astrocytes (Fig. 1D). Altogether these results show that, similar to its function in neurons $(36,37)$, Kidins220 is a crucial regulator of BDNF-dependent TrkB signaling also in astrocytes.

The expression of full-length TrkB and the activation of BDNF-dependent kinase pathways are reduced in wild-type postnatal astrocytes

Astrocytes undergo important physiological changes from the embryonic development to the postnatal period, accompanied by variations in the expression pattern of several signaling proteins (38). In order to study the developmental changes associated to the BDNF-TrkB system, we prepared primary astrocyte cultures from P0-P1 pups from Kidins $220^{+/ l o x} \mathrm{X}$ Kidins $220^{+/ l o x}$ breeding couples, which allowed us to have both Kidins $220^{+/+}$and Kidins $220^{\text {lox/lox }}$ animals in the same litter. We chose this strategy since the full knockout of Kidins220 causes embryonic lethality, thus precluding the possibility of performing postnatal dissection $(37,39)$. We first compared the expression levels of full-length and truncated TrkB receptors in wild type embryonic and postnatal preparations and found a specific reduction of the full-length isoform in postnatal cultures, leading to a decreased fulllength/truncated ratio compared to embryonic cells (Fig. 2A). Exposure of wild type postnatal cultures to $50 \mathrm{ng} / \mathrm{ml}$ BDNF led to an appreciable increase in Akt and MAPK1/2 phosphorylation, although the fold-increase in MAPK1/2 phosphorylation was lower than that observed in embryonic cultures (1.2-fold versus 2.5-fold at $30 \mathrm{~min}$, compare Fig. 2B and 1C), a likely consequence of the lower expression of the full-length TrkB receptor. Similar results were observed when a lower concentration of BDNF (1 ng/ml) was used (Suppl. Fig. 2). 
Kidins220 controls the expression of both full-length and truncated TrkB receptors, but is dispensable for the activation BDNF-dependent kinase pathways in postnatal astrocytes

Primary Kidins $220^{\text {lox/lox }}$ cultures were subsequently infected with lentiviruses expressing either the active form of the Cre recombinase to induce Kidins 220 depletion, or a functionally inactive Cre ( $\Delta \mathrm{Cre})$ as control ((40); see Materials and Methods for details). We refer to these cultures as 'Kidins220-depleted' (Kidins220 ${ }^{\text {lox/lox-Cre }}$ ) and 'control' (Kidins220 $20^{\text {lox/lox-SCre }}$ ). Cre-induced Kidins220 depletion in postnatal preparations led to a reduction of both full-length and truncated TrkB expression, with the full-length/truncated ratio remaining unaltered, a result in full agreement with that obtained on embryonic cultures (Fig. 3A). We then analyzed the signaling capability of postnatal cultures in the presence or absence of Kidins220. The basal expression levels of MAPK1/2, PLC $\gamma$ and Akt were not affected by Kidins220 depletion (Fig. 3B). In contrast to the data obtained in embryonic cultures, removal of Kidins220 in postnatal cultures did not affect the activation of BDNF-induced MAPK1/2, PLC $\gamma$ and Akt phosphorylation (Fig. 3C and Suppl. Fig. 3).

Altogether, the data presented in Figure 2 and 3 show that (i) the expression of full-length TrkB and the activation of kinase pathways upon exposure to BDNF are reduced in wild type postnatal astrocytes compared to embryonic cells; and (ii) the expression of both full-length and truncated TrkB receptors is further reduced in the absence of Kidins220, however the limited activation of kinase pathways induced by BDNF is not impacted upon Kidins220 depletion.

\section{Depletion of Kidins220 impairs BDNF-induced $\left[\mathrm{Ca}^{2+}\right]_{i}$ transients in postnatal astrocytes}

We subsequently investigated the role played by Kidins 220 in BDNF-induced $\left[\mathrm{Ca}^{2+}\right]_{\mathrm{i}}$ signaling by monitoring BDNF-induced $\left[\mathrm{Ca}^{2+}\right]_{\mathrm{i}}$ transients in astrocytes (7). In embryonic cultures, very few cells responded to BDNF stimulation $\left(9.8 \%\right.$ for $+/+$ and $7.4 \%$ for Kidins $220^{-/-}$, Fig. $\left.\mathbf{4 A}\right)$ and responsive cells displayed modest $\left[\mathrm{Ca}^{2+}\right]_{\mathrm{i}}$ variations (Fig. 4B-C). In contrast, around 30-35\% of cells in postnatal cultures responded to BDNF with sizable $\left[\mathrm{Ca}^{2+}\right]_{i}$ peaks (Fig. 4D-F). Whereas the percentage of responding cells was not affected by Kidins220 depletion (Fig. 4D), the average amplitude of the BDNF-induced $\left[\mathrm{Ca}^{2+}\right]_{\mathrm{i}}$ transients was significantly reduced in absence of Kidins 220 (Fig. 4E and F; \# 
$\mathrm{p}<0.05$ genotype effect). To investigate the contribution of the different isoforms of TrkB in this process, we repeated the same experiments in the presence of either the tyrosine kinase blocker K252a (37) to inhibit specifically the full-length TrkB isoform, or the TrkB antagonist ANA-12 (41) to block both full-length and truncated TrkB receptors. Pre-incubation of the cells with K-252a did not affect the percentage of BDNF-responding cells (Fig. 4D, shaded). However, the amplitude of the observed $\left[\mathrm{Ca}^{2+}\right]_{\mathrm{i}}$ influx was reduced independently of the presence of Kidins220 (Fig. 4F and G; genotype effect: $\mathrm{p}=0.0432(\#)$ K-252a treatment effect: $\mathrm{p}<0.0001 \quad(* * *)$; treatment $\mathrm{x}$ genotype interaction: $\mathrm{p}=0.2197$, see legend for more details), suggesting that the BDNF-induced $\left[\mathrm{Ca}^{2+}\right]_{\mathrm{i}}$ variations involved full-length TrkB receptors. BDNF-stimulation in presence of ANA-12 did not induce any response, confirming that the residual signal was attributable to TrkB-T1 activation (Fig. 4H). Furthermore, the observed response was completely dependent on PLC $\gamma$ activity, as shown by the absence of BDNF-induced $\left[\mathrm{Ca}^{2+}\right]_{\mathrm{i}}$ transients in the presence of the specific PLC $\gamma$ inhibitor U73122 (Fig. 4I).

Altogether, these data show that BDNF induce modest $\left[\mathrm{Ca}^{2+}\right]_{\mathrm{i}}$ events in embryonic astrocytes, while appreciable $\left[\mathrm{Ca}^{2+}\right]_{\mathrm{i}}$ responses are elicited in postnatal cells. Postnatal $\left[\mathrm{Ca}^{2+}\right]_{\mathrm{i}}$ transients are fully dependent on TrkB receptors, as shown by their complete inhibition in the presence of ANA-12. Interestingly, part of this response is mediated by the full-length receptor, as shown by the partial reduction of amplitude in the presence of K-252a. Moreover, our results show that Kidins220 plays an active role in this process, as in its absence the amplitude of $\left[\mathrm{Ca}^{2+}\right]_{i}$ events is reduced.

\section{BDNF stimuli promote gene transcription in postnatal astrocyte cells}

To shed light on the functional effects of BDNF signaling in astroglia, we analyzed the transcriptional profile of cultures treated with $1 \mathrm{ng} / \mathrm{ml}$ BDNF for three days. We focused on four genes whose expression is crucial for astrocytes physiology: the glutamate transporter 1 (GLT-1), the inwardly rectifying $\mathrm{K}^{+}$channel 4.1 (Kir4.1), aquaporin 4 (Aqp4) and connexin 43 (Cnx43) (Fig. 5). While the expression of GLT-1, Kir4.1 or Cnx43 was not sensitive to BDNF, at least within the time frame of our experiment, Aqp4 transcription was selectively reduced upon chronic BDNF stimulation (* $\mathrm{p}<0.05$, treatment effect). While Kidins 220 deficiency did not alter the response to BDNF, it 
selectively and markedly reduced the expression of Kir4.1 independently of BDNF (\#\# p<0.01, genotype effect).

These data suggest that: (i) chronic exposure to BDNF alters the expression of specific astrocyte genes, and (ii) Kidins220 plays a role in the maintenance of astrocyte homeostasis and potassium buffering function by modulating the expression of Kir4.1. 


\section{DISCUSSION}

The main findings of this work can be summarized as follows: (i) primary cultured astrocytes express predominantly the TrkB-T1 isoform, however they do express a small amount of full-length TrkB receptor that is signaling competent, as shown by the BDNF-induced activation of the MAPK pathway, and whose expression declines in postnatal cells; (ii) astrocyte cultures show a stagedependent shift in their response to BDNF, whereby embryonic cells mostly respond by activating intracellular phosphorylation pathways (MAPK1/2, PCL $\gamma$ and Akt) and are not competent to induce sizable BDNF-dependent $\left[\mathrm{Ca}^{2+}\right]_{\mathrm{i}}$ transients, while postnatal cells respond to BDNF stimuli inducing robust variations of $\left[\mathrm{Ca}^{2+}\right]_{\mathrm{i}}$ and limited activation of intracellular signaling cascades; (iii) the scaffold protein Kidins 220 participates to TrkB signaling both in embryonic and postnatal astrocytes and modulates the expression of fundamental astrocyte genes such as the inward rectifier potassium channel Kir 4.1. A schematic representation of our results is shown in Fig. 6.

Extensive literature supports the notion that TrkB-T1 is the main isoform expressed in astroglia $(12,42)$; however experimental evidence also points at a limited expression of the full-length receptor, at least in vitro $(16,17)$. Moreover, reactive astrocytes express the full-length TrkB receptor upon CNS injury (18) and chronic diseases $(19,20)$, raising the question of whether the astrocyte expression of full-length TrkB under pathological conditions recapitulates intracellular pathways that are normally active during development. Re-activation of developmental programs is indeed a known feature of reactive astrocytes (43) and of astrocyte-derived tumors such as gliomas (44-46), and the BDNF/TrkB pathway is overexpressed in several brain tumors (47). Consistent with previous observations (17), our data show that the expression of full-length TrkB decreases from embryonic to postnatal astrocytes, supporting the idea that the intracellular pathways activated by this receptor could be active during embryogenesis and re-activated in the presence of neural pathologies. This finding is potentially relevant in that it shows that cultured astrocytes retain - to some extent - the identity of the tissue from which they were initially isolated $(48,49)$.

For what concerns the signaling pathways activated by BDNF in astrocytes, our data indicate that activation of the canonical (MAPK1/2, PCL $\gamma$ and Akt) phosphorylation pathways is predominant in embryonic cultures, while the same cascades are activated to a reduced extent in postnatal cells, in 
agreement with the reduced expression of full-length TrkB. Our embryonic and postnatal cultures are predominantly composed of astrocytes, with only a small $(<10 \%)$ contamination of other glial cells, mostly microglia (33). Although we cannot exclude that a small component of the activated pathways observed in western blot experiments is coming from cells other than astrocytes, the strong induction of protein phosphorylation observed upon BDNF treatment by western blotting, together with the increased phospho-TrkB staining in GFAP+ cells revealed by fluorescence microscopy analysis indicate that the observed changes in intracellular signaling pathways are predominantly attributable to astrocytes. The mechanisms underlying BDNF-induced $\left[\mathrm{Ca}^{2+}\right]_{\mathrm{i}}$ transients become fully functional in postnatal astrocytes; indeed, only modest BDNF-induced $\left[\mathrm{Ca}^{2+}\right]_{i}$ elevations are observed in embryonic cultures. We hypothesize that such limited response could be ascribable to a still immature coupling between the $\mathrm{Ca}^{2+}$ receptors and channels on endoplasmic reticulum and on the plasma membrane, which together coordinate the store-operated $\mathrm{Ca}^{2+}$ entry (SOCE) mechanism in mature astrocytes (3). The $\left[\mathrm{Ca}^{2+}\right]_{\mathrm{i}}$ transients observed in postnatal cells upon BDNF administration comprise two components. The first, which accounts for about $40 \%$ of the observed signal, is mediated by fulllength $\operatorname{TrkB}$ and is sensitive to pre-incubation with K-252a. The complete ablation of $\left[\mathrm{Ca}^{2+}\right]_{\mathrm{i}}$ transients observed in the presence of the pan-TrkB inhibitor ANA-12 reveals that the second and predominant component is dependent on TrkB-T1, as previously reported (7). The complete dependence of $\left[\mathrm{Ca}^{2+}\right]_{i}$ variations on PLC $\gamma$ suggests that the pathways activated by both receptors converge on SOCE. While only $40 \%$ of postnatal astrocytes were responsive to BDNF in terms of $\left[\mathrm{Ca}^{2+}\right]_{\mathrm{i}}$ transients, the majority of GFAP+ cells were immunoreactive for full-length TrkB phosphorylation in embryonic cultures. Our calcium imaging data confirm that the capability of astrocytes to initiate BDNF-induced $\left[\mathrm{Ca}^{2+}\right]_{i}$ transients varies depending on the degree of differentiation of the cells. Thus, we propose that the expression of full-length TrkB is a general feature of embryonic cells; whether BDNF-responsive astrocytes in postnatal cultures represent a specific subpopulation endowed with distinct physiological functions is a relevant issue that will be addressed in future investigations. Interestingly, chronic treatment with BDNF reduced Aqp4 expression, indicating that the neurotrophin is capable to induce long-term changes in astrocytes, 
potentially impacting on their physiology and on their capability to maintain nervous system homeostasis.

The scaffold protein Kidins220 is highly expressed in the nervous system during embryonic development and plays a fundamental role in modulating neuronal survival and maturation; indeed, its complete ablation leads to embryonic lethality with widespread apoptosis in the central and peripheral nervous system $(37,39)$. Kidins 220 function has been extensively studied in neurons, where it contributes to several fundamental processes such as neuronal differentiation (50), excitability (51) and synaptic plasticity (52), mostly by mediating BDNF stimuli through its interaction with Trk and p75 receptors $(36,53,54)$. In the absence of Kidins220, the expression of both TrkB isoforms is reduced in embryonic as well as in postnatal astrocyte cultures. In embryonic cultures, Kidins $220^{-/}$astrocytes are characterized by reduced sustained activation of the MAPK pathway suggesting that similar to neurons $(36,37)$, Kidins220 modulates MAPK activation downstream of full-length TrkB in astrocytes. In postnatal astrocytes, Kidins 220 contributes to both full-length and truncated TrkB-induced $\left[\mathrm{Ca}^{2+}\right]_{i}$ signaling, as both components are reduced in Kidins220-depleted cells. Of note, the interaction between Kidins220 and TrkB involves the transmembrane domain of the receptor (36) that is shared between the two receptor isoforms. Our gene expression analysis revealed reduced expression of Kir4.1 in Kidins220-depleted astrocytes. Interestingly, similar results have been recently described in cultured astrocytes lacking TrkB-T1 (912), further supporting the notion that Kidins 220 and TrkB receptors are part of the same signaling system. Together with the increased expression of the transient receptor potential cation channel subfamily V member 4 (TRPV4) that we previously described (33), this observation suggests that the deficiency of Kidins220 subjects astrocytes to a global stress reaction and contributes to explain the developmental and activity impairments observed in wild type neurons co-cultured with Kidins $220^{-/-}$ cells (33).

Overall, our work contributes to define the complex and debated mechanisms of neurotrophin signaling in astrocytes, showing that - at least in vitro - both full-length and truncated TrkB receptors are competent to activate distinct intracellular signaling pathways at distinct phases of astrocyte development. Furthermore, we identified Kidins220 as one of the cellular components endowing full- 
length and truncated TrkB receptor their signaling specificity. Our future studies will address how these findings will translate in vivo, under physiological and pathological conditions. In recent years, mutations in the KIDINS220 gene have been associated with severe neurodevelopmental pathologies, whose main symptoms are intellectual disability and spastic paraplegia (55-61). A better understanding of the physiological functions of neurotrophins and Kidins220 in neurons and glial cells is instrumental to address the molecular pathways leading to this severe neurological disorder, which are currently completely unknown. 


\section{MATERIALS AND METHODS}

\section{Animals}

All embryos used in this study were obtained from crosses of Kidins $220^{+/-}$mice $(37,52)$ in the C57BL/6 background. Mice were mated overnight and separated in the morning. The development of the embryos was timed from the detection of a vaginal plug, which was considered day 0.5. Postnatal cultures were prepared from P0-P1 pups obtained from crosses of Kidins $220^{+/ l o x}$ mice on the C57BL/6 background. All experiments were carried out in accordance with the guidelines established by the European Community Council (Directive 2010/63/EU of 22 September 2010) and were approved by the Italian Ministry of Health.

\section{Antibodies}

The following primary antibodies were used: rabbit polyclonal anti-Kidins220 (GSC16, \#AB34790, Abcam), rabbit polyclonal anti-TrkB (\#07-225, Millipore), rabbit monoclonal anti-phosphorylated TrkB (Tyr516, \#4619, Cell Signaling) rabbit monoclonal anti-GAPDH (14C10, \#2118, Cell signaling), rabbit monoclonal anti-phosphorylated MAPK1/2 (Thr202/Tyr204, \#4377, Cell signaling), rabbit polyclonal anti-MAPK1/2 (\#06-182, Millipore), rabbit monoclonal anti-phosphorylated Akt (Ser473, \#4058, Cell signaling), rabbit polyclonal anti-Akt (\#9272, Cell signaling), rabbit polyclonal anti-phosphorylated PLC $\gamma$ (Tyr783, \#2821, Cell signaling), rabbit polyclonal anti-PLC $\gamma$ (\#2822, Cell signaling), mouse monoclonal anti-glial fibrillary acidic protein (GFAP, \#G3893, Sigma-Aldrich).

Secondary antibodies for western blot analysis were ECL Plex goat anti-rabbit IgG-Cy5 (PA45012, GE Healthcare), ECL Plex goat anti-mouse IgG-Cy3 (PA43009, GE Healthcare), HRPconjugated goat anti-rabbit antibodies (\#31460, ThermoFisher scientific) and HRP-conjugated goat anti-mouse antibodies (\#31430, ThermoFisher scientific). Fluorescently conjugated secondary antibodies for immunocytochemistry were from Molecular Probes (Thermo-Fisher Scientific; Alexa Fluor 488, \#A11029; Alexa Fluor 647, \#A21450). Hoechst (\#B2261, Sigma-Aldrich) was used to stain nuclei. 


\section{Primary astrocyte culture}

E18.5 or P0-P1 cortices were dissected in ice-cold PBS, incubated with trypsin $0.25 \%$ and $1 \mathrm{mg} / \mathrm{ml}$ DNase I for $30 \mathrm{~min}$ at $37^{\circ} \mathrm{C}$, and mechanically dissociated. Cells were then re-suspended and plated on poly-D-lysine-coated flasks or glass coverslips, in MEM medium containing 10\% FBS, 2 mM glutamine, $33 \mathrm{mM}$ glucose and antibiotics (astrocyte culture medium). After $24 \mathrm{~h}$, the medium was removed and replaced with fresh culture medium. After one week, half of the medium was replaced with fresh culture medium. Embryonic and postnatal cultures were composed of about $90 \%$ astrocytes and were totally devoid of neurons (33).

\section{Lentivirus production and infection procedures}

HEK293T cells were maintained in Iscove's Modified Dulbecco's Medium supplemented with 10\% FBS, $2 \mathrm{mM}$ Glutamine, $100 \mathrm{U} / \mathrm{ml}$ penicillin and $0.1 \mathrm{mg} / \mathrm{ml}$ streptomycin in a $5 \% \mathrm{CO}_{2}$ humidified incubator at $37{ }^{\circ} \mathrm{C}$. Cells were transfected with the $\Delta 8.9$ encapsidation plasmid, the VSVG envelope plasmid and the pLenti-PGK-Cre-EGFP or pLenti-PGK- $\Delta$ Cre-EGFP plasmids (40) using the calcium phosphate method. The transfection medium was replaced by fresh medium after $16 \mathrm{~h}$. Supernatants were collected 36 to $48 \mathrm{~h}$ after transfection, centrifuged to remove cell debris, passed through a 0.45 $\mu \mathrm{m}$ filter and ultracentrifuged $2 \mathrm{~h}$ at $20,000 \times \mathrm{g}$ at $4^{\circ} \mathrm{C}$. Viral pellets were re-suspended in PBS, aliquoted and stored at $-80{ }^{\circ} \mathrm{C}$ until use.

Confluent postnatal cultures were trypsinized and seeded on 6-well plates or glass coverslips coated with poly-D-lysine for subsequent experiments. Cells were infected 3 days later with lentiviruses encoding catalytically dead $(\Delta \mathrm{Cre})$ or active Cre recombinase with the lowest infectious dose capable of transducing $\geq 95 \%$ of cells (dilution range 1:500 to 1:800) and used for experiments $\geq 7$ days after transduction.

\section{Calcium imaging}

Astrocytes at 3 DIV or at 7-8 DIV after lentivirus infection were loaded with $1 \mu \mathrm{g} / \mathrm{ml}$ Fura-2-AM (\#F1221, ThermoFisher) in astrocyte culture medium for $30 \mathrm{~min}$ at $37^{\circ} \mathrm{C}$. Subsequently, cells were washed in recording buffer (10 mM HEPES pH 7.4, $150 \mathrm{mM} \mathrm{NaCl}, 3 \mathrm{mM} \mathrm{KCl}, 1 \mathrm{mM} \mathrm{MgCl} \mathrm{Mg}_{2}, 10 \mathrm{mM}$ 
Glucose and $\left.2 \mathrm{mM} \mathrm{CaCl}{ }_{2}\right) 30 \mathrm{~min}$ at $37{ }^{\circ} \mathrm{C}$ to allow hydrolysis of the esterified groups. Coverslips with cells were mounted on the imaging chamber and loaded with $0.45 \mathrm{ml}$ of recording buffer. Fura-2loaded cultures were observed with an inverted Leica 6000 microscope using a HCX PL APO lambda blue 63.0x1.40 oil-immersion objective. For analyzing BDNF-evoked $\mathrm{Ca}^{2+}$ transients, $50 \mu 1$ of BDNF solution (final concentration $20 \mathrm{ng} / \mathrm{ml}$, as reported in (7), \#B3795, Sigma) were manually added to the culture medium $15 \mathrm{~s}$ after the beginning of the recordings. Where indicated, cells were preincubated with 150 nM K-252a (tyrosine kinase blocker, \#K1639, Sigma), $1 \mu$ M ANA-12 (TrkB receptor antagonist, \#SML0209, Sigma), 10 MM U73122 (PLC $\gamma$ inhibitor, \#U6756, Sigma) or $10 \mu$ M U73343 (inactive analog, \#U6881, Sigma) for $10 \mathrm{~min}$ before the beginning of the recordings. Samples were excited at 340 and $380 \mathrm{~nm}$ and images of fluorescence emission at $510 \mathrm{~nm}$ were acquired using a Hamamatsu-C9100-02-LNK00 camera. Calcium levels were estimated from background subtracted ratio images (340/380nm) of Fura-2-loaded astrocytes at the cell body level according to the equation of Grynkiewicz (62):

$$
\left[\mathrm{Ca}^{2+}\right]=K_{d} \times \frac{R-R_{\min }}{R_{\text {max }}-R} \times \frac{F_{\text {max }}^{380}}{F_{\text {min }}^{380}}
$$

where $R$ is the measured $340 / 380 \mathrm{~nm}$ ratio; $R_{\min }$ and $R_{\max }$ are the ratios in the absence of $\mathrm{Ca}^{2+}$ or when Fura-2 is saturated by $\mathrm{Ca}^{2+}$, and $\mathrm{F}^{380}{ }_{\max }$ and $\mathrm{F}^{380}{ }_{\min }$ are the fluorescence intensity of $380 \mathrm{~nm}$ excitation at $0 \mathrm{Ca}^{2+}$ and at $\mathrm{Ca}^{2+}$ saturation. To determine the $\mathrm{Kd}$ in our system, in situ calibration was performed by using $1 \mu \mathrm{M}$ of the $\mathrm{Ca}^{2+}$-ionophore ionomycin in recording buffer containing an increasing concentration of $\mathrm{Ca}^{2+}$, ranging from $1 \mathrm{nM}$ to $10 \mathrm{mM}$. $\left[\mathrm{Ca}^{2+}\right]_{\mathrm{i}}$ transients were defined for $\mathrm{R} / \mathrm{R}_{0} \geq 0.025$.

\section{Biochemical techniques}

Cells were washed once in ice-cold PBS and lysed in RIPA buffer (50 mM Tris-HCl pH 7.4, $150 \mathrm{mM}$ $\mathrm{NaCl}, 2 \mathrm{mM}$ EDTA, 1\% NP40, 0.1\% SDS) plus protease and phosphatase inhibitors (complete EDTA-free protease inhibitors, Roche Diagnostic; serine/threonine phosphatase inhibitor and tyrosine phosphatase inhibitor, Sigma). After centrifugation at $16,000 \times \mathrm{g}$ for $15 \mathrm{~min}$ at $4{ }^{\circ} \mathrm{C}$, protein concentration was quantified by using the BCA Protein Assay kit (ThermoFisher Scientific). SDSPAGE and western blotting were performed by using precast 4-12\% NuPAGE Novex Bis-Tris Gels 
(Invitrogen). After incubation with primary antibodies, membranes were incubated with fluorescently conjugated secondary antibodies and revealed by a Typhoon Variable Mode Imager (GE Healthcare) or with HRP-conjugated secondary antibodies and ECL Prime Western Blotting System (\#RPN2106, GE Healthcare) and imaged using a ChemiDoc imaging system (Biorad). Immunoreactive bands were quantified by using the ImageJ software. The fold change activation was calculated by first making the ratio of the intensity of phosphorylated bands to the total amount of corresponding protein for each sample, and then by dividing the phospho:total ratio of the treated samples by the phospho:total ratio of untreated control samples.

\section{Immunocytochemistry and image analysis}

Cells were fixed in $4 \%$ PFA for 15 min, then washed in PBS. Cells were subsequently permeabilized with $0.2 \%$ Triton-X 100 in PBS for 10 min at room temperature (RT) then incubated with primary antibodies diluted in PBS $1 \%$ BSA overnight at $4^{\circ} \mathrm{C}$ or $2 \mathrm{~h}$ at RT. After washes in PBS, cells were incubated with fluorescent secondary antibodies diluted in PBS 1\% BSA. After washes, coverslips were mounted with Mowiol.

Confocal stacks were acquired with a Leica SP8 using a 40X oil immersion objective (NA 1.40), with $1 \mu \mathrm{m}$ between optical sections. Images were analyzed using the ImageJ software. The maximal fluorescence intensities of in-focus stacks were z-projected and the resulting images were automatically thresholded. Regions of interests (ROIs) were manually drawn around the borders of GFAP-positive cells in the red channel and fluorescence intensity was measured in the green channel (P-TrkB). Quantification was performed on 18-20 fields per condition from three independent cell preparations. Data are reported as the average P-TrkB fluorescence intensity of all GFAP+ cells in each field.

\section{Chronic BDNF treatment, RNA extraction and RT-qPCR}

Three days after lentiviral infection, Kidins $220^{\text {lox/lox }}$ astrocytes cultures were serum starved overnight then treated with $1 \mathrm{ng} / \mathrm{ml} \mathrm{BDNF}$ on the following morning or left untreated. Treatment was repeated on the next two days and total RNA was extracted the following day with the QIAzol lysis reagent 
(Qiagen). The corresponding cDNAs were prepared by reverse transcription of $1 \mu \mathrm{g}$ of RNA using the SuperScript III First-Strand Synthesis System (Invitrogen) with an oligo-dT primer according to the manufacturer's instructions. The resulting cDNAs were used as a template for RT-qPCR using a CFX96 Real-Time PCR Detection System (Biorad) with a SYBR Green master mix (Qiagen). Thermal cycling parameters were $5 \mathrm{~min}$ at $95{ }^{\circ} \mathrm{C}$, followed by 40 cycles of $95{ }^{\circ} \mathrm{C}$ for $15 \mathrm{~s}$, and $60{ }^{\circ} \mathrm{C}$ for $45 \mathrm{~s}$. The relative quantification in gene expression was determined using the $\Delta \Delta \mathrm{Ct}$ method. Data were normalized to Transferrin receptor protein 1 (TRFR), TATA-box-binding protein (TBP), and Tubulin beta-2A (TUBB2) by the multiple internal control gene method with GeNorm algorithm (63). Sequences of the primers used are listed in Supplementary Table 1.

\section{Statistical analysis}

Data are presented as means \pm S.E.M. throughout the text. The distribution of the data was assessed using the D'Agostino-Pearson omnibus normality test. When comparing two groups unpaired twosided Student's $t$-test and one-sample $t$-test were used, and equality of variances tested through the $\mathrm{F}$ test. When more than two groups were compared, two-way ANOVA followed by the Tukey's post hoc multiple comparison test was performed to assess significance as indicated in figure legends, and equality of variances tested through the Brown-Forsythe's and Bartlett's test. Alpha levels for all tests were $0.05 \%$ (95\% confidence intervals). No statistical methods were used to predetermine sample sizes, however sample sizes in this work (indicated in figure legends) are similar to those previously reported in the literature for similar experiments. The ROUT method with $\mathrm{Q}=1 \%$ was used to identify outliers for exclusion from analysis. All statistical procedures were performed using GraphPad Prism 7 software (GraphPad Software, Inc). 


\section{List of Supplementary Materials}

Supplementary Figure 1. Activation of signaling pathways upon administration of $1 \mathrm{ng} / \mathrm{ml} \mathrm{BDNF}$ in embryonic astrocytes.

Supplementary Figure 2. Activation of signaling pathways upon administration of $1 \mathrm{ng} / \mathrm{ml}$ BDNF in wild type postnatal astrocytes.

Supplementary Figure 3. Activation of signaling pathways upon administration of $1 \mathrm{ng} / \mathrm{ml}$ BDNF in Kidins220-deficient postnatal astrocytes.

Supplementary Table 1. List of primers used for the RT-qPCR analysis. 


\section{REFERENCES}

1. M. Santello, N. Toni, A. Volterra, Astrocyte function from information processing to cognition and cognitive impairment. Nat Neurosci 22, 154-166 (2019); published online EpubFeb (10.1038/s41593-018-0325-8).

2. E. Colombo, C. Farina, Astrocytes: Key Regulators of Neuroinflammation. Trends Immunol 37, 608-620 (2016); published online EpubSep (10.1016/j.it.2016.06.006).

3. Y. Okubo, Astrocytic $\mathrm{Ca}(2+)$ signaling mediated by the endoplasmic reticulum in health and disease. J Pharmacol Sci 144, 83-88 (2020); published online EpubOct (10.1016/j.jphs.2020.07.006).

4. A. Verkhratsky, M. Matteoli, V. Parpura, J. P. Mothet, R. Zorec, Astrocytes as secretory cells of the central nervous system: idiosyncrasies of vesicular secretion. EMBO J 35, 239-257 (2016); published online EpubFeb 1 (10.15252/embj.201592705).

5. H. Park, M. M. Poo, Neurotrophin regulation of neural circuit development and function. Nature reviews. Neuroscience 14, 7-23 (2013); published online EpubJan (10.1038/nrn3379).

6. S. Poyhonen, S. Er, A. Domanskyi, M. Airavaara, Effects of Neurotrophic Factors in Glial Cells in the Central Nervous System: Expression and Properties in Neurodegeneration and Injury. Front Physiol 10, 486 (2019)10.3389/fphys.2019.00486.

7. C. R. Rose, R. Blum, B. Pichler, A. Lepier, K. W. Kafitz, A. Konnerth, Truncated TrkB-T1 mediates neurotrophin-evoked calcium signalling in glia cells. Nature 426, $74-78$ (2003); published online EpubNov 6 (10.1038/nature01983).

8. K. Ohira, H. Kumanogoh, Y. Sahara, K. J. Homma, H. Hirai, S. Nakamura, M. Hayashi, A truncated tropomyosin-related kinase B receptor, T1, regulates glial cell morphology via Rho GDP dissociation inhibitor 1. J Neurosci 25, 1343-1353 (2005); published online EpubFeb 9 (10.1523/JNEUROSCI.4436-04.2005).

9. S. H. Vaz, T. N. Jorgensen, S. Cristovao-Ferreira, S. Duflot, J. A. Ribeiro, U. Gether, A. M. Sebastiao, Brain-derived neurotrophic factor (BDNF) enhances GABA transport by modulating the trafficking of GABA transporter-1 (GAT-1) from the plasma membrane of rat 
cortical astrocytes. J Biol Chem 286, $40464-40476$ (2011); published online EpubNov 25 (10.1074/jbc.M111.232009).

10. R. I. Aroeira, A. M. Sebastiao, C. A. Valente, BDNF, via truncated TrkB receptor, modulates GlyT1 and GlyT2 in astrocytes. Glia 63, 2181-2197 (2015); published online EpubDec (10.1002/glia.22884).

11. K. Ohira, N. Funatsu, K. J. Homma, Y. Sahara, M. Hayashi, T. Kaneko, S. Nakamura, Truncated TrkB-T1 regulates the morphology of neocortical layer I astrocytes in adult rat brain slices. Eur J Neurosci 25, 406-416 (2007); published online EpubJan (10.1111/j.14609568.2007.05282.x).

12. L. M. Holt, R. D. Hernandez, N. L. Pacheco, B. Torres Ceja, M. Hossain, M. L. Olsen, Astrocyte morphogenesis is dependent on BDNF signaling via astrocytic TrkB.T1. Elife 8, (2019); published online EpubAug 21 (10.7554/eLife.44667).

13. E. Colombo, C. Cordiglieri, G. Melli, J. Newcombe, M. Krumbholz, L. F. Parada, E. Medico, R. Hohlfeld, E. Meinl, C. Farina, Stimulation of the neurotrophin receptor TrkB on astrocytes drives nitric oxide production and neurodegeneration. J Exp Med 209, 521-535 (2012); published online EpubMar 12 (10.1084/jem.20110698).

14. J. J. Matyas, C. M. O'Driscoll, L. Yu, M. Coll-Miro, S. Daugherty, C. L. Renn, A. I. Faden, S. G. Dorsey, J. Wu, Truncated TrkB.T1-Mediated Astrocyte Dysfunction Contributes to Impaired Motor Function and Neuropathic Pain after Spinal Cord Injury. J Neurosci 37, 39563971 (2017); published online EpubApr 5 (10.1523/JNEUROSCI.3353-16.2017).

15. S. Yanpallewar, G. Fulgenzi, F. Tomassoni-Ardori, C. Barrick, L. Tessarollo, Delayed onset of inherited ALS by deletion of the BDNF receptor TrkB.T1 is non-cell autonomous. Experimental neurology, 113576 (2020); published online EpubDec 23 (10.1016/j.expneurol.2020.113576).

16. D. F. Condorelli, T. Salin, P. Dell' Albani, G. Mudo, M. Corsaro, T. Timmusk, M. Metsis, N. Belluardo, Neurotrophins and their trk receptors in cultured cells of the glial lineage and in white matter of the central nervous system. $J$ Mol Neurosci 6, 237-248 (1995)10.1007/BF02736783. 
17. E. Climent, M. Sancho-Tello, R. Minana, D. Barettino, C. Guerri, Astrocytes in culture express the full-length Trk-B receptor and respond to brain derived neurotrophic factor by changing intracellular calcium levels: effect of ethanol exposure in rats. Neurosci Lett 288, 5356 (2000); published online EpubJul 7 (10.1016/s0304-3940(00)01207-6)

18. R. J. McKeon, J. Silver, T. H. Large, Expression of full-length trkB receptors by reactive astrocytes after chronic CNS injury. Exp Neurol 148, 558-567 (1997); published online EpubDec (10.1006/exnr.1997.6698).

19. V. Soontornniyomkij, G. Wang, C. A. Pittman, C. A. Wiley, C. L. Achim, Expression of brain-derived neurotrophic factor protein in activated microglia of human immunodeficiency virus type 1 encephalitis. Neuropathol Appl Neurobiol 24, 453-460 (1998); published online EpubDec (10.1046/j.1365-2990.1998.00134.x).

20. C. Stadelmann, M. Kerschensteiner, T. Misgeld, W. Bruck, R. Hohlfeld, H. Lassmann, BDNF and gp145trkB in multiple sclerosis brain lesions: neuroprotective interactions between immune and neuronal cells? Brain 125, 75-85 (2002); published online EpubJan (10.1093/brain/awf015).

21. J. Saba, F. Lopez Couselo, J. Turati, L. Carniglia, D. Durand, A. de Laurentiis, M. Lasaga, C. Caruso, Astrocytes from cortex and striatum show differential responses to mitochondrial toxin and BDNF: implications for protection of striatal neurons expressing mutant huntingtin. J Neuroinflammation 17, 290 (2020); published online EpubOct 6 (10.1186/s12974-02001965-4).

22. M. Bergami, S. Santi, E. Formaggio, C. Cagnoli, C. Verderio, R. Blum, B. Berninger, M. Matteoli, M. Canossa, Uptake and recycling of pro-BDNF for transmitter-induced secretion by cortical astrocytes. J Cell Biol 183, 213-221 (2008); published online EpubOct 20 (10.1083/jcb.200806137).

23. B. Vignoli, G. Battistini, R. Melani, R. Blum, S. Santi, N. Berardi, M. Canossa, Peri-Synaptic Glia Recycles Brain-Derived Neurotrophic Factor for LTP Stabilization and Memory Retention. Neuron 92, 873-887 $\quad$ (2016); published online EpubNov 23 (10.1016/j.neuron.2016.09.031). 
24. A. Rousseaud, C. Delepine, J. Nectoux, P. Billuart, T. Bienvenu, Differential Expression and Regulation of Brain-Derived Neurotrophic Factor (BDNF) mRNA Isoforms in Brain Cells from Mecp2(308/y) Mouse Model. J Mol Neurosci 56, 758-767 (2015); published online EpubAug (10.1007/s12031-014-0487-0).

25. M. Kinboshi, T. Mukai, Y. Nagao, Y. Matsuba, Y. Tsuji, S. Tanaka, K. Tokudome, S. Shimizu, H. Ito, A. Ikeda, A. Inanobe, Y. Kurachi, S. Inoue, Y. Ohno, Inhibition of Inwardly Rectifying Potassium (Kir) 4.1 Channels Facilitates Brain-Derived Neurotrophic Factor (BDNF) Expression in Astrocytes. Front Mol Neurosci 10, 408 (2017)10.3389/fnmol.2017.00408.

26. S. Inoue, M. Susukida, K. Ikeda, K. Murase, K. Hayashi, Dopaminergic transmitter upregulation of brain-derived neurotrophic factor (BDNF) and nerve growth factor (NGF) synthesis in mouse astrocytes in culture. Biochem Biophys Res Commun 238, 468-472 (1997); published online EpubSep 18 (10.1006/bbrc.1997.7324).

27. Y. Y. Jean, L. D. Lercher, C. F. Dreyfus, Glutamate elicits release of BDNF from basal forebrain astrocytes in a process dependent on metabotropic receptors and the PLC pathway. Neuron Glia Biol 4, 35-42 (2008); published online EpubFeb (10.1017/S1740925X09000052).

28. S. Miklic, D. M. Juric, M. Carman-Krzan, Differences in the regulation of BDNF and NGF synthesis in cultured neonatal rat astrocytes. Int J Dev Neurosci 22, 119-130 (2004); published online EpubMay (10.1016/j.jidevneu.2004.03.001).

29. R. N. Saha, X. Liu, K. Pahan, Up-regulation of BDNF in astrocytes by TNF-alpha: a case for the neuroprotective role of cytokine. J Neuroimmune Pharmacol 1, 212-222 (2006); published online EpubSep (10.1007/s11481-006-9020-8).

30. F. Zafra, D. Lindholm, E. Castren, J. Hartikka, H. Thoenen, Regulation of brain-derived neurotrophic factor and nerve growth factor mRNA in primary cultures of hippocampal neurons and astrocytes. J Neurosci 12, $4793-4799$ (1992); published online EpubDec (10.1523/JNEUROSCI.12-12-04793.1992) 
31. V. E. Neubrand, F. Cesca, F. Benfenati, G. Schiavo, Kidins220/ARMS as a functional mediator of multiple receptor signalling pathways. J Cell Sci 125, 1845-1854 (2012); published online EpubApr 15 (jcs.102764 [pii] 10.1242/jcs.102764).

32. J. Scholz-Starke, F. Cesca, Stepping Out of the Shade: Control of Neuronal Activity by the Scaffold Protein Kidins220/ARMS. Front Cell Neurosci 10, 68 (2016)10.3389/fncel.2016.00068).

33. F. Jaudon, M. Chiacchiaretta, M. Albini, S. Ferroni, F. Benfenati, F. Cesca, Kidins220/ARMS controls astrocyte calcium signaling and neuron-astrocyte communication. Cell Death Differ, (2019); published online EpubOct 17 (10.1038/s41418-019-0431-5).

34. L. A. Hutton, J. deVellis, J. R. Perez-Polo, Expression of p75NGFR TrkA, and TrkB mRNA in rat C6 glioma and type I astrocyte cultures. J Neurosci Res 32, 375-383 (1992); published online EpubJul (10.1002/jnr.490320309).

35. D. F. Condorelli, P. Dell'Albani, G. Mudo, T. Timmusk, N. Belluardo, Expression of neurotrophins and their receptors in primary astroglial cultures: induction by cyclic AMPelevating agents. $J$ Neurochem 63, 509-516 (1994); published online EpubAug $(10.1046 / j \cdot 1471-4159.1994 .63020509 . x)$

36. J. C. Arevalo, H. Yano, K. K. Teng, M. V. Chao, A unique pathway for sustained neurotrophin signaling through an ankyrin-rich membrane-spanning protein. EMBO $J \mathbf{2 3}$, 2358-2368 (2004); published online EpubJun 16 (10.1038/sj.emboj.7600253).

37. F. Cesca, A. Yabe, B. Spencer-Dene, J. Scholz-Starke, L. Medrihan, C. H. Maden, H. Gerhardt, I. R. Orriss, P. Baldelli, M. Al-Qatari, M. Koltzenburg, R. H. Adams, F. Benfenati, G. Schiavo, Kidins220/ARMS mediates the integration of the neurotrophin and VEGF pathways in the vascular and nervous systems. Cell Death Differ 19, 194-208 (2012); published online EpubFeb (cdd2011141 [pii] 10.1038/cdd.2011.141).

38. G. Dallerac, J. Zapata, N. Rouach, Versatile control of synaptic circuits by astrocytes: where, when and how? Nature reviews. Neuroscience 19, $729-743$ (2018); published online EpubDec (10.1038/s41583-018-0080-6). 
39. F. Cesca, A. Yabe, B. Spencer-Dene, A. Arrigoni, M. Al-Qatari, D. Henderson, H. Phillips, M. Koltzenburg, F. Benfenati, G. Schiavo, Kidins220/ARMS is an essential modulator of cardiovascular and nervous system development. Cell Death Dis 2, e226 (2011)cddis2011108 [pii] 10.1038/cddis.2011.108).

40. P. S. Kaeser, L. Deng, Y. Wang, I. Dulubova, X. Liu, J. Rizo, T. C. Sudhof, RIM proteins tether $\mathrm{Ca} 2+$ channels to presynaptic active zones via a direct PDZ-domain interaction. Cell 144, 282-295 (2011); published online EpubJan 21 (10.1016/j.cell.2010.12.029).

41. M. Cazorla, J. Premont, A. Mann, N. Girard, C. Kellendonk, D. Rognan, Identification of a low-molecular weight TrkB antagonist with anxiolytic and antidepressant activity in mice. $J$ Clin Invest 121, 1846-1857 (2011); published online EpubMay (10.1172/JCI43992).

42. B. M. Fenner, Truncated TrkB: beyond a dominant negative receptor. Cytokine Growth Factor Rev 23, 15-24 (2012); published online EpubFeb-Apr (10.1016/j.cytogfr.2012.01.002).

43. A. Buffo, I. Rite, P. Tripathi, A. Lepier, D. Colak, A. P. Horn, T. Mori, M. Gotz, Origin and progeny of reactive gliosis: A source of multipotent cells in the injured brain. Proc Natl Acad Sci U S A 105, 3581-3586 (2008); published online EpubMar 4 (10.1073/pnas.0709002105).

44. T. N. Ignatova, V. G. Kukekov, E. D. Laywell, O. N. Suslov, F. D. Vrionis, D. A. Steindler, Human cortical glial tumors contain neural stem-like cells expressing astroglial and neuronal markers in vitro. Glia 39, 193-206 (2002); published online EpubSep (10.1002/glia.10094).

45. R. Galli, E. Binda, U. Orfanelli, B. Cipelletti, A. Gritti, S. De Vitis, R. Fiocco, C. Foroni, F. Dimeco, A. Vescovi, Isolation and characterization of tumorigenic, stem-like neural precursors from human glioblastoma. Cancer Res 64, 7011-7021 (2004); published online EpubOct 1 (10.1158/0008-5472.CAN-04-1364).

46. D. J. Silver, D. A. Steindler, Common astrocytic programs during brain development, injury and cancer. Trends Neurosci 32, 303-311 (2009); published online EpubJun (10.1016/j.tins.2009.01.008).

47. L. Meng, B. Liu, R. Ji, X. Jiang, X. Yan, Y. Xin, Targeting the BDNF/TrkB pathway for the treatment of tumors. Oncol Lett 17, 2031-2039 (2019); published online EpubFeb (10.3892/ol.2018.9854). 
48. J. P. Schwartz, N. Nishiyama, Neurotrophic factor gene expression in astrocytes during development and following injury. Brain Res Bull 35, 403-407 (1994)10.1016/03619230(94)90151-1).

49. V. W. Wu, N. Nishiyama, J. P. Schwartz, A culture model of reactive astrocytes: increased nerve growth factor synthesis and reexpression of cytokine responsiveness. J Neurochem 71, 749-756 (1998); published online EpubAug (10.1046/j.1471-4159.1998.71020749.x).

50. A. M. Higuero, L. Sanchez-Ruiloba, L. E. Doglio, F. Portillo, J. Abad-Rodriguez, C. G. Dotti, T. Iglesias, Kidins220/ARMS modulates the activity of microtubule-regulating proteins and controls neuronal polarity and development. J Biol Chem 285, 1343-1357 (2010); published online EpubJan 8 (10.1074/jbc.M109.024703).

51. F. Cesca, A. Satapathy, E. Ferrea, T. Nieus, F. Benfenati, J. Scholz-Starke, Functional Interaction between the Scaffold Protein Kidins220/ARMS and Neuronal Voltage-Gated Na+ Channels. J Biol Chem 290, 18045-18055 (2015); published online EpubJul 17 (10.1074/jbc.M115.654699).

52. J. Scholz-Starke, F. Cesca, G. Schiavo, F. Benfenati, P. Baldelli, Kidins220/ARMS Is a Novel Modulator of Short-Term Synaptic Plasticity in Hippocampal GABAergic Neurons. PLoS One 7, e35785 (2012)10.1371/journal.pone.0035785PONE-D-11-26082 [pii]).

53. H. Kong, J. Boulter, J. L. Weber, C. Lai, M. V. Chao, An evolutionarily conserved transmembrane protein that is a novel downstream target of neurotrophin and ephrin receptors. J Neurosci 21, 176-185 (2001); published online EpubJan 1 (21/1/176 [pii]).

54. J. C. Arevalo, D. B. Pereira, H. Yano, K. K. Teng, M. V. Chao, Identification of a switch in neurotrophin signaling by selective tyrosine phosphorylation. J Biol Chem 281, 1001-1007 (2006); published online EpubJan 13 (10.1074/jbc.M504163200).

55. D. J. Josifova, G. R. Monroe, F. Tessadori, E. de Graaff, B. van der Zwaag, S. G. Mehta, D. D. D. Study, M. Harakalova, K. J. Duran, S. M. Savelberg, I. J. Nijman, H. Jungbluth, C. C. Hoogenraad, J. Bakkers, N. V. Knoers, H. V. Firth, P. L. Beales, G. van Haaften, M. M. van Haelst, Heterozygous KIDINS220/ARMS nonsense variants cause spastic paraplegia, 
intellectual disability, nystagmus, and obesity. Hum Mol Genet 25, 2158-2167 (2016); published online EpubJun 01 (10.1093/hmg/ddw082).

56. I. L. Mero, H. H. Mork, Y. Sheng, A. Blomhoff, G. L. Opheim, A. Erichsen, M. D. Vigeland, K. K. Selmer, Homozygous KIDINS220 loss-of-function variants in fetuses with cerebral ventriculomegaly and limb contractures. Hum Mol Genet 26, 3792-3796 (2017); published online EpubOct $1(10.1093 / \mathrm{hmg} / \mathrm{ddx} 263)$.

57. L. Yang, W. Zhang, J. Peng, F. Yin, Heterozygous KIDINS220 mutation leads to spastic paraplegia and obesity in an Asian girl. Eur J Neurol 25, e53-e54 (2018); published online EpubMay (10.1111/ene.13600).

58. F. Cesca, G. Schiavo, F. Benfenati, Kidins220/ARMS transgenic lines could be instrumental in the understanding of the molecular mechanisms leading to spastic paraplegia and obesity. Eur J Neurol 25, e107 (2018); published online EpubSep (10.1111/ene.13693).

59. M. Zhao, Y. J. Chen, M. W. Wang, X. H. Lin, E. L. Dong, W. J. Chen, N. Wang, X. Lin, Genetic and Clinical Profile of Chinese Patients with Autosomal Dominant Spastic Paraplegia. Mol Diagn Ther, (2019); published online EpubOct 19 (10.1007/s40291-019-00426-w).

60. S. H. El-Dessouky, M. Y. Issa, M. M. Aboulghar, H. M. Gaafar, A. E. Elarab, M. I. Ateya, H. H. Omar, C. Beetz, M. S. Zaki, Prenatal delineation of a distinct lethal fetal syndrome caused by a homozygous truncating KIDINS220 variant. Am J Med Genet A 182, 2867-2876 (2020); published online EpubDec (10.1002/ajmg.a.61858).

61. V. Jacquemin, M. Antoine, S. Duerinckx, A. Massart, J. Desir, C. Perazzolo, M. Cassart, D. Thomas, V. Segers, S. Lecomte, M. Abramowicz, I. Pirson, TrkA mediates effect of novel KIDINS220 mutation in human brain ventriculomegaly. Hum Mol Genet, (2020); published online EpubNov 18 (10.1093/hmg/ddaa245).

62. G. Grynkiewicz, M. Poenie, R. Y. Tsien, A new generation of $\mathrm{Ca} 2+$ indicators with greatly improved fluorescence properties. J Biol Chem 260, 3440-3450 (1985).

63. J. Vandesompele, K. De Preter, F. Pattyn, B. Poppe, N. Van Roy, A. De Paepe, F. Speleman, Accurate normalization of real-time quantitative RT-PCR data by geometric averaging of 
bioRxiv preprint doi: https://doi.org/10.1101/2021.02.10.430582; this version posted February 10, 2021. The copyright holder for this preprint (which was not certified by peer review) is the author/funder. All rights reserved. No reuse allowed without permission.

multiple internal control genes. Genome Biol 3, RESEARCH0034 (2002); published online EpubJun 18 (10.1186/gb-2002-3-7-research0034). 
Acknowledgements. We kindly acknowledge: drs. A. Mehilli, D. Moruzzo, and R. Navone for help in the maintenance, breeding and genotyping of the Kidins220 mouse strains; drs. R. Ciancio and I. Dallorto for the administrative support.

Funding. The study was supported by research grants from: IRCCS Ospedale Policlinico San Martino (Ricerca Corrente and "5x1000" to FC and FB), the Italian Ministry of University and Research (PRIN 2017-A9MK4R to FB), Compagnia di San Paolo (grant \#2013.1014 to FC).

Author contributions: F.J. performed the biochemical analysis and $\mathrm{Ca}^{2+}$ imaging experiments in embryonic astrocytes, part of the biochemical analysis and of the $\mathrm{Ca}^{2+}$ imaging experiments in postnatal astrocytes; M.A. performed immunocytochemistry in embryonic astrocytes, part of the biochemical analysis and of the $\mathrm{Ca}^{2+}$ imaging experiments in postnatal astrocytes, gene expression analysis; S.F. contributed to the designing of experiments and to discuss the results; F.B. contributed to the designing of experiments, to discuss the results and supported the project; F.C. designed the project, supervised all the experiments and discussed the results. All author contributed to writing the paper.

Competing interests. The authors declare that they do not have any competing financial interests in relation to the work described.

Data and materials availability. The datasets used and/or analyzed during the current study are available from the corresponding author on reasonable request. 


\section{FIGURE LEGENDS}

A

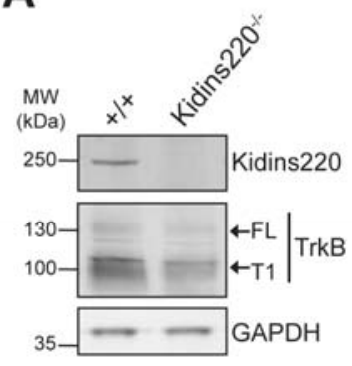

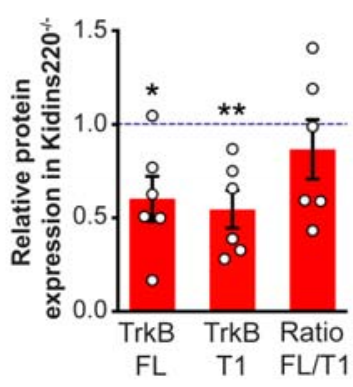

B

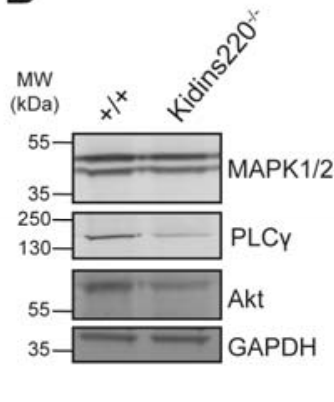

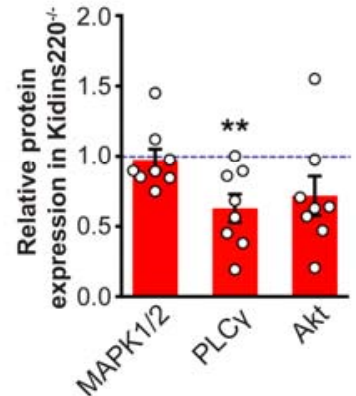

C

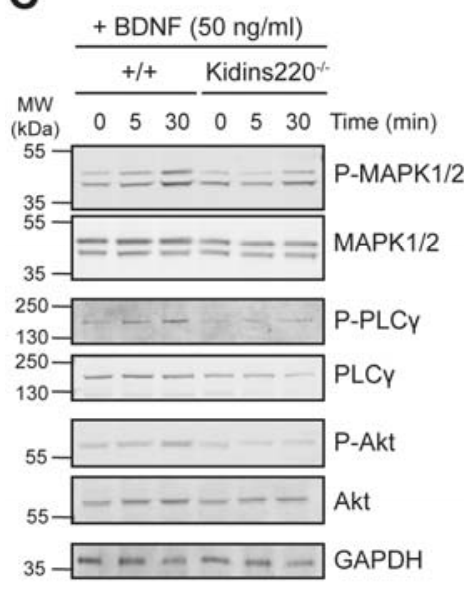

Basal

BDNF-stimulated
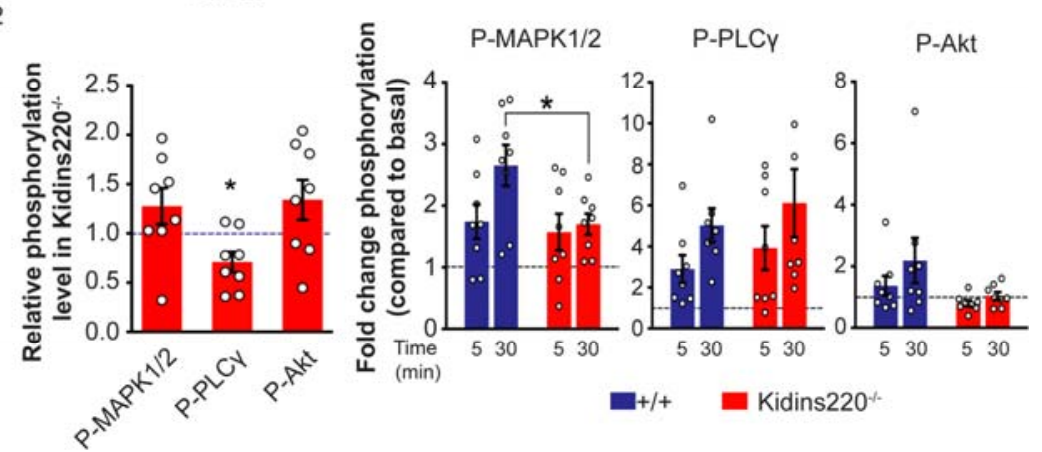

D

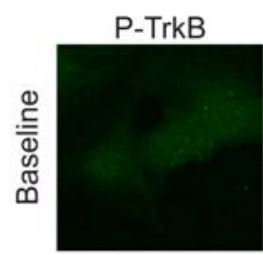

GFAP
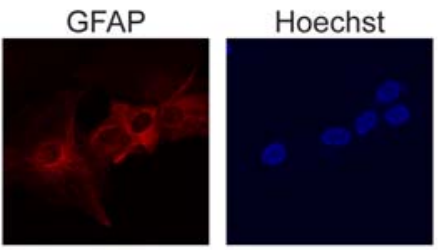

Merge

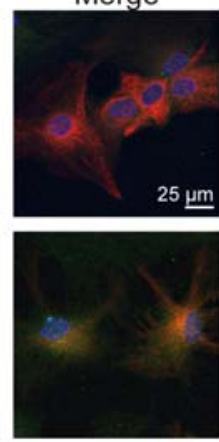

Figure 1 


\section{Figure 1. TrkB-dependent BDNF signaling is impaired in Kidins220 ${ }^{-/-}$embryonic astrocytes.}

$(\mathbf{A , B})$ Protein extracts from wild type (+/+) and Kidins $220^{-/-}$embryonic astrocyte cultures at 15 DIV were analyzed by western blotting using anti-Kidins220 and anti-TrkB antibodies (A); anti-MAPK1/2, anti-PLC $\gamma$ and anti-Akt antibodies (B). Representative immunoblots are shown on the left; quantification of immunoreactive bands is on the right. The intensity of bands from Kidins $220^{-1-}$ samples was normalized to the corresponding bands from wild type samples within the same nitrocellulose membrane. ${ }^{*} \mathrm{p}<0.05,{ }^{*} \mathrm{p}<0.01$, one sample Student's $t$-test, $\mathrm{n}=6$ (A) and $\mathrm{n}=8$ (B) wild type and Kidins $220^{-/-}$cultures. (C) Wild type and Kidins $220^{-{ }_{-1}}$ astrocyte cultures were treated with 50 $\mathrm{ng} / \mathrm{ml} \mathrm{BDNF}$ for 5 and $30 \mathrm{~min}$ or left untreated (time 0). Lysates were analyzed for phosphorylated MAPK1/2 (Thr202/Tyr204), PLC $\gamma$ (Tyr783) and Akt (Ser473). Membranes were subsequently stripped and re-probed for the total amount of the same protein. Left: Representative immunoblots. Middle: Basal phosphorylation levels of MAPK1/2, PLC $\gamma$ and Akt in untreated wild type and Kidins $220^{-/-}$lysates. Data were analyzed as in (A,B). Right: Time dependence of MAPK1/2, PLC $\gamma$ and Akt phosphorylation upon BDNF stimulation in wild type and Kidins $220^{-/-}$astrocytes. The graphs express the fold change activation of MAPK1/2, PLC $\gamma$ and Akt compared to the untreated phosphorylation levels for each genotype, set to 1 (dashed line in all graphs). The fold change activation was calculated first by making the ratio of the intensity of phosphorylated bands to the total amount of protein for each sample then by dividing the phospho:total ratio of the treated samples by the phospho:total ratio of untreated control samples. For MAPK, we report the sum of MAPK1 and MAPK2 immunoreactivity. *p<0.05, unpaired Student's $t$-test, $\mathrm{n}=8$ for both wild type and Kidins $220^{-/-}$ cultures. In all experiments, GAPDH was used as a loading control. (D) Left: Representative confocal images of untreated and BDNF-treated ( $1 \mathrm{ng} / \mathrm{ml}$ for $5 \mathrm{~min}$ ) wild type astrocytes stained with antipTrkB (Tyr516, green) and anti-GFAP (red) antibodies, and with Hoechst to visualize nuclei. Scale bars, $25 \mu \mathrm{m}$. Right: quantification of pTrkB fluorescence intensity in GFAP positive cells. ${ }^{*} \mathrm{p}<0.05$, unpaired Student's $t$-test, $\mathrm{n}=20$ and 18 fields for untreated and BDNF-treated cells, respectively, from three independent preparations. Data are reported as the average pTrkB fluorescence intensity of all GFAP+ cells in each field. Values are expressed as mean \pm S.E.M. in all panels. 

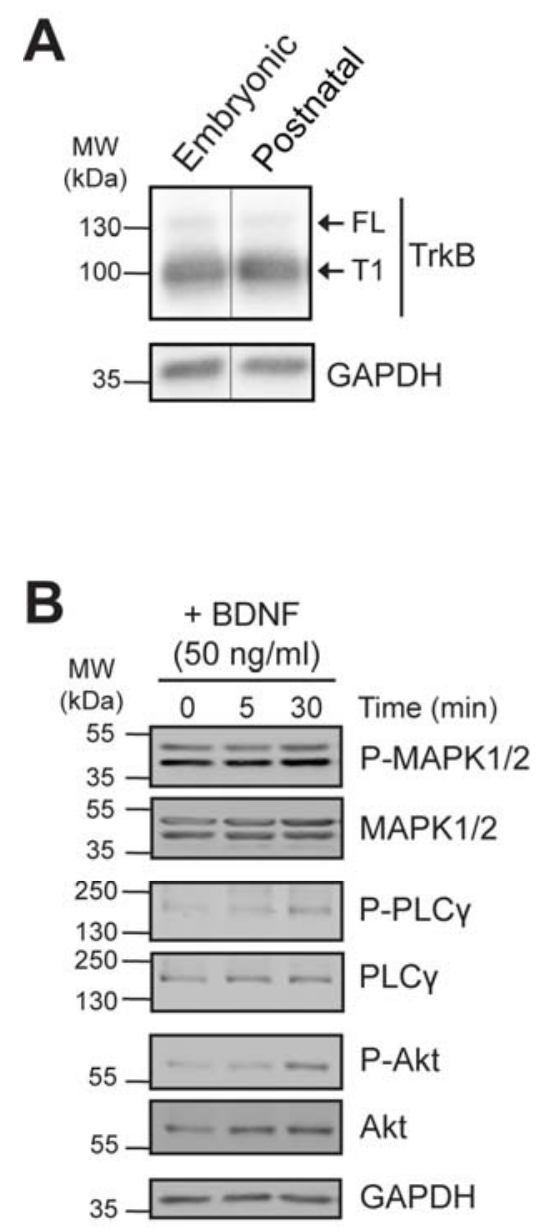
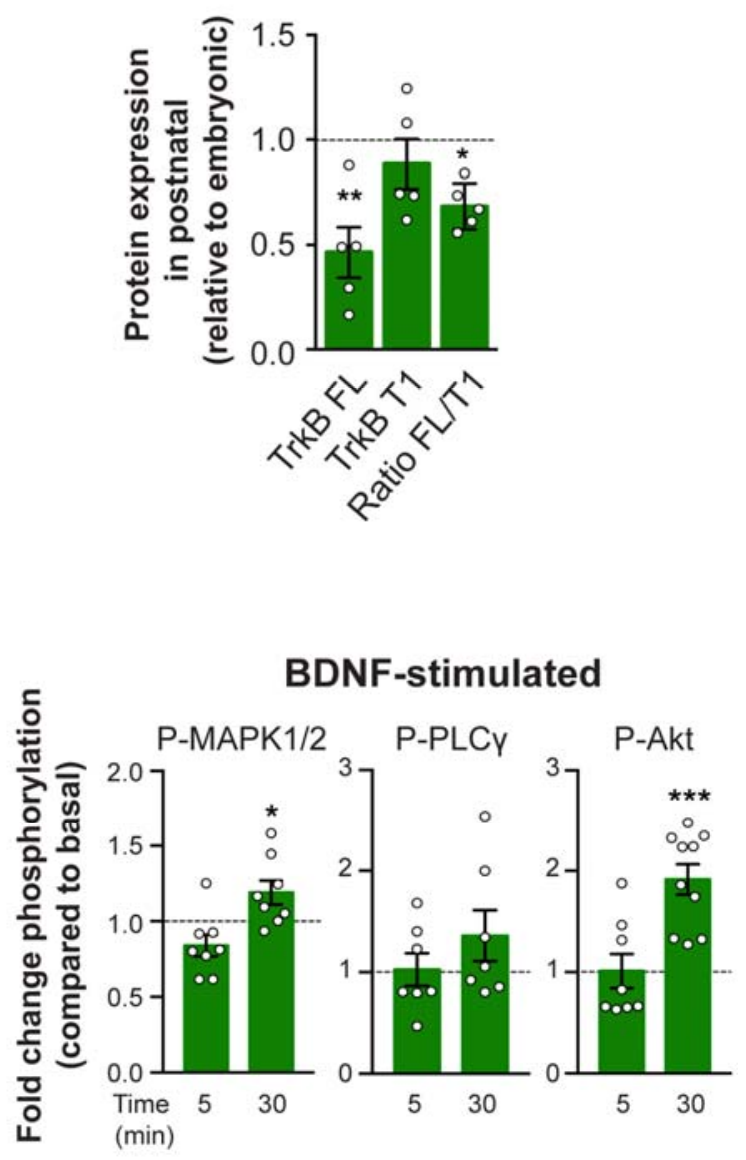

Figure 2

Figure 2. Expression of full-length TrkB is reduced in postnatal astrocytes.

(A) Protein extracts from wild type embryonic and postnatal cultures were analyzed by western blotting with anti-TrkB antibodies. A representative immunoblot is shown in the left panel; quantification of immunoreactive bands is in the right panel. The intensity of bands from postnatal samples was normalized to the corresponding bands from wild type embryonic samples within the same nitrocellulose membrane. ${ }^{*} \mathrm{p}<0.05,{ }^{*} \mathrm{p}<0.01$, one sample Student's $t$-test, $\mathrm{n}=5$ wild type embryonic and postnatal cultures. (B) Postnatal wild type astrocyte cultures were treated with $50 \mathrm{ng} / \mathrm{ml}$ BDNF for 5 and $30 \mathrm{~min}$ or left untreated (time 0). Lysates were analyzed for phosphorylated MAPK1/2 (Thr202/Tyr204) and Akt (Ser473). Membranes were subsequently stripped and re-probed for the total amount of the same protein. Left: Representative immunoblots. Right: Time dependence of MAPK1/2 and Akt phosphorylation in response to BDNF in wild type 
and Kidins $220^{\text {lox/lox }}$ astrocytes. The graphs express the fold change activation of MAPK1/2 and Akt compared to the untreated phosphorylation levels for each genotype, set to 1 (dashed line in all graphs). The fold change activation was calculated as described in Fig. 1. For MAPK, we report the sum of MAPK1 and MAPK2 immunoreactivity. ${ }^{*} \mathrm{p}<0.05,{ }^{* * *} \mathrm{p}<0.001$, one sample Student's $t$-test compared to baseline, $n=7-8$ independent cultures. Values are expressed as mean \pm S.E.M. in all panels.

A

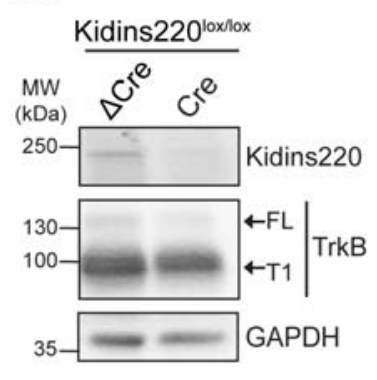

C $\frac{+\operatorname{BDNF}(50 \mathrm{ng} / \mathrm{ml})}{\frac{\operatorname{Kidins} 220^{10 \times / 10 x}}{\Delta C^{2}}}$

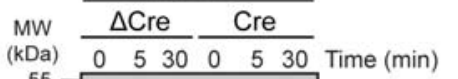

$35-\approx$ ニ

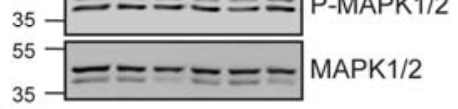

$130-150-P L C Y$

$130-250-2 \ldots$ PLCY

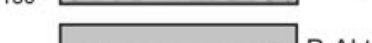

P-Akt

-
B
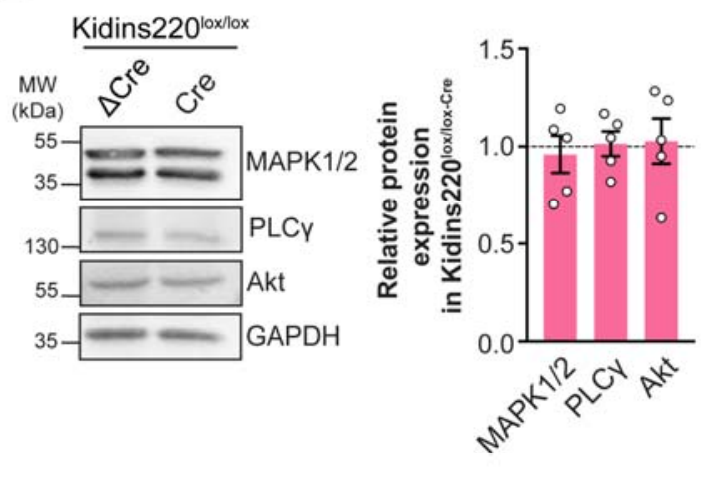

BDNF-stimulated

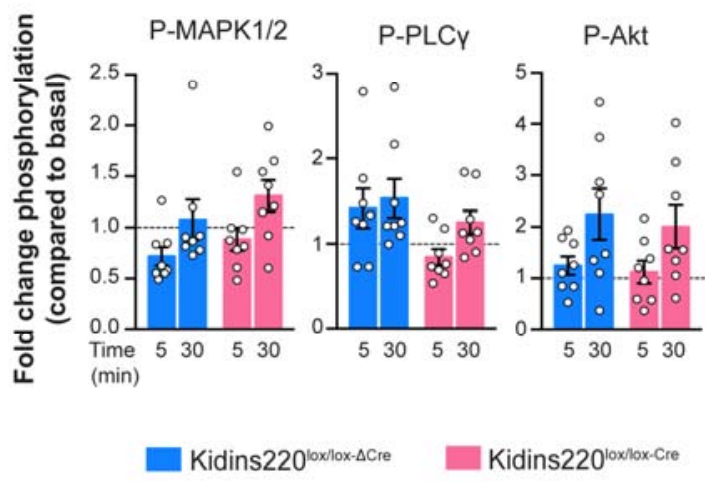

Figure 3

Figure 3. Removal of Kidins220 in postnatal astrocyte cultures does not alter TrkB-dependent BDNF signaling.

$($ A,B $)$ Protein extracts from Kidins $220^{\operatorname{lox} / l o x}$ P0-P1 astrocyte cultures infected with lentiviruses encoding catalytically dead ( $\Delta \mathrm{Cre})$ or active Cre recombinase were analyzed by western blotting using 
anti-Kidins220 and anti-TrkB antibodies (A); anti-MAPK1/2, anti-PLC $\gamma$ and anti-Akt antibodies (B). Representative immunoblots are shown on the left; quantification of immunoreactive bands is on the right. The intensity of bands from Kidins $220^{\text {lox/lox-Cre }}$ samples was normalized to the corresponding bands from Kidins $220^{\text {lox/lox- } \Delta \text { Cre }}$ samples within the same nitrocellulose membrane. $* * p<0.01$, ***p $<0.001$, one sample Student's $t$-test, $\mathrm{n}=5-7$ Kidins $220^{\text {lox/lox }}$ cultures. (C) Kidins $220^{\text {lox/lox-Cre }}$ and Kidins $220^{\text {lox/lox- } \Delta \text { Cre }}$ astrocytes were treated with $50 \mathrm{ng} / \mathrm{ml}$ BDNF for 5 and $30 \mathrm{~min}$ or left untreated (time 0). Lysates were analyzed for phosphorylated MAPK1/2 (Thr202/Tyr204) and Akt (Ser473). Membranes were subsequently stripped and re-probed for the total amount of the same protein. Left: Representative immunoblots. Middle: Basal phosphorylation levels of MAPK1/2 and Akt in untreated lysates. Data were analyzed as in (A,B). Right: Time dependence of MAPK1/2 and Akt phosphorylation upon BDNF stimulation in Kidins $220^{\operatorname{lox} / / \operatorname{lox}-\mathrm{Cre}}$ and Kidins $220^{\text {lox/lox-ACre }}$ astrocytes. The graphs express the fold change activation of MAPK1/2 and Akt compared to the untreated phosphorylation levels for each genotype, set to 1 (dashed line in all graphs). The fold change activation was calculated as described in Fig. 1. For MAPK, we report the sum of MAPK1 and MAPK2 immunoreactivity. $\mathrm{p}>0.05$, unpaired Student's $t$-test, $\mathrm{n}=8$ independent Kidins $220^{\text {lox/lox }}$ cultures. Values are expressed as mean \pm S.E.M. in all panels. 
A
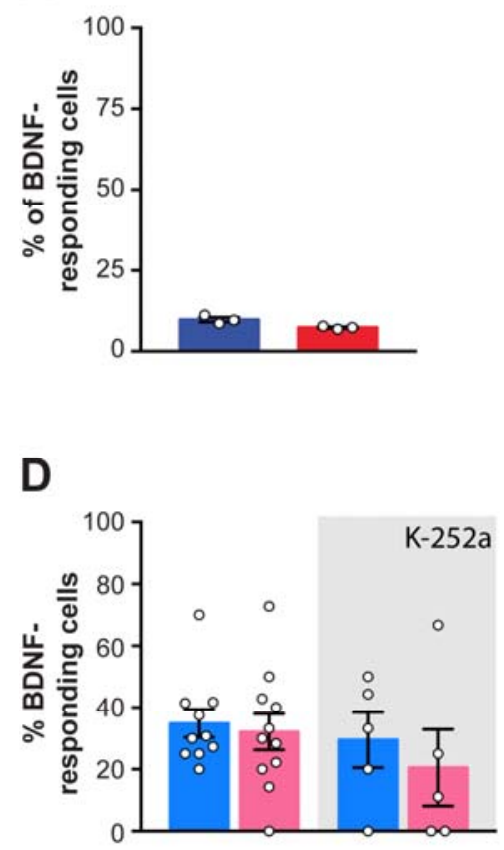

G

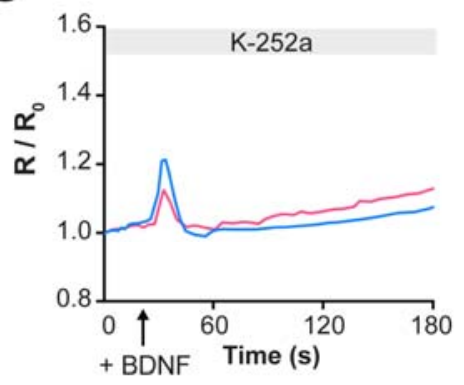

B

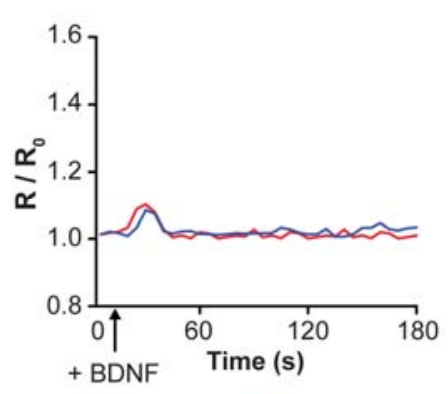

C

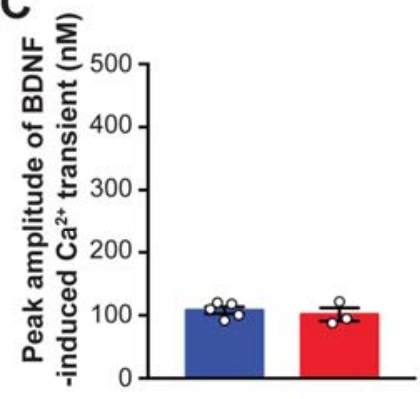

$\square+1+\quad$ Kidins220\%

E
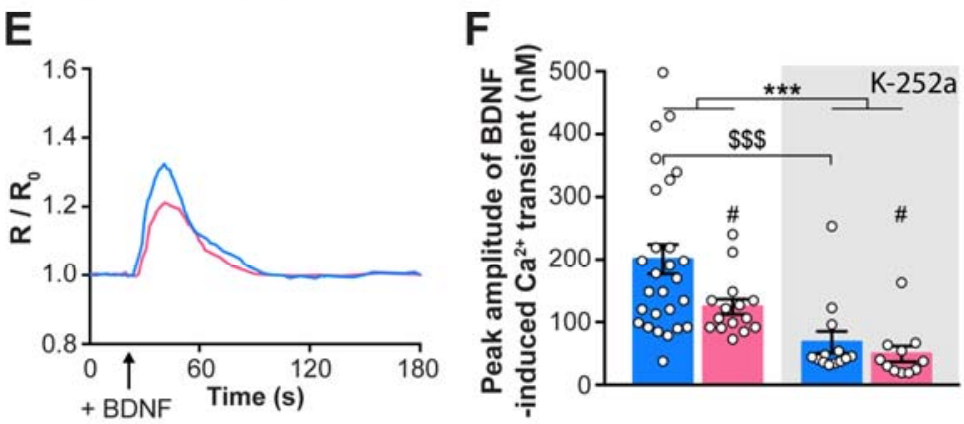

Kidins220 $20^{\text {loxlox }}-\Delta$ Cre

H

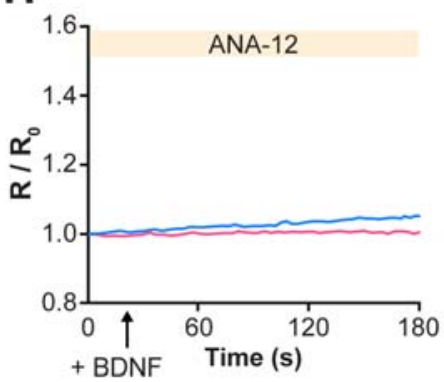

I

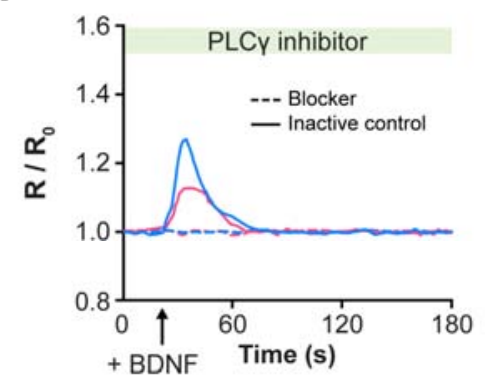

Figure 4

Figure 4. Depletion of Kidins220 in postnatal cultures impairs BDNF-induced calcium transients.

(A-C) BDNF-induced $\left[\mathrm{Ca}^{2+}\right]_{\mathrm{i}}$ transients in embryonic wild type and Kidins $220^{-/-}$astrocytes. (A) Percentage of cells displaying $\mathrm{Ca}^{2+}$ transients in response to BDNF (20 $\left.\mathrm{ng} / \mathrm{ml}\right)$ stimulation. $\mathrm{n}=3$ for both wild type and Kidins $220^{-/-}$cultures. $\left[\mathrm{Ca}^{2+}\right]_{\mathrm{i}}$ transients were defined when $\mathrm{R} / \mathrm{R}_{0} \geq 0.025$. (B,C) Time-course of calcium transients $(\mathbf{B})$ and peak amplitude $(\mathbf{C})$ of BDNF-evoked $\mathrm{Ca}^{2+}$ levels in wild type and Kidins $220^{-/-}$astrocytes. (D-I) BDNF-induced $\left[\mathrm{Ca}^{2+}\right]_{\mathrm{i}}$ transients in postnatal Kidins $220^{\text {lox/lox-Cre }}$ and Kidins $220^{\text {lox/lox- } \Delta \mathrm{Cre}}$ astrocytes. (D) Percentage of cells displaying $\mathrm{Ca}^{2+}$ transients in response to BDNF $(20 \mathrm{ng} / \mathrm{ml})$ stimulation in the presence or absence of the tyrosine kinase blocker K-252a. $\mathrm{n}=5$ 
and 10 Kidins $220^{\text {lox/lox }}$ cultures with and without K-252a, respectively. (E,F) Time-course of calcium transients (E) and peak amplitude $(\mathbf{F})$ of BDNF-evoked $\mathrm{Ca}^{2+}$ influx in Kidins $220^{\text {lox/lox-Cre }}$ and Kidins $220^{\text {lox/lox- } \Delta \text { Cre }}$ astrocytes in the absence or presence of K-252a. Two-way ANOVA followed by Tukey's multiple comparison test; ***p<0.001 versus untreated, $\# \mathrm{p}<0.05$ versus Kidins $220^{\text {lox/lox}-\Delta \text { Cre }}$, $\$ \$ \$ \mathrm{p}<0.001$ versus untreated Kidins $220^{\text {lox/lox- } \Delta \text { Cre }}$ (genotype effect: $\mathrm{F}_{(1,62)}=4.262, \mathrm{p}=0.0432$ (\#); K-252a treatment effect: $\mathrm{F}_{(1,62)}=20.17, \mathrm{p}<0.0001(* * *)$; treatment $\mathrm{x}$ genotype interaction: $\mathrm{F}_{(1,62)}=1.538$, $\mathrm{p}=0.2197), \mathrm{n}=27$ and 15 cells from 6 independent cultures for Kidins $220^{\text {lox/lox }-\Delta \mathrm{Cre}}$ and Kidins $220^{\text {lox/lox- }}$ ${ }^{\text {Cre }}$ cells in absence of K-252a, and n=13 and 11 from 6 independent cultures for Kidins $220^{\text {lox/lox }-\Delta \text { Cre }}$ and Kidins $220^{\text {lox/lox-Cre }}$ cells in presence of K-252a. (G-I) Time-course of calcium transients evoked by BDNF in Kidins $220^{\text {lox/lox- } \Delta \text { Cre }}$ and Kidins $220^{\text {lox/lox-Cre }}$ astrocytes in the presence of the TrkB receptor kinase inhibitor K-252a (G), the pan-TrkB antagonist ANA-12 (H), the active PLC $\gamma$ inhibitor U73122 (dashed lines) or its inactive analogue $\mathrm{U} 73343$ (solid lines) (I). Values are expressed as mean \pm S.E.M. in all panels.

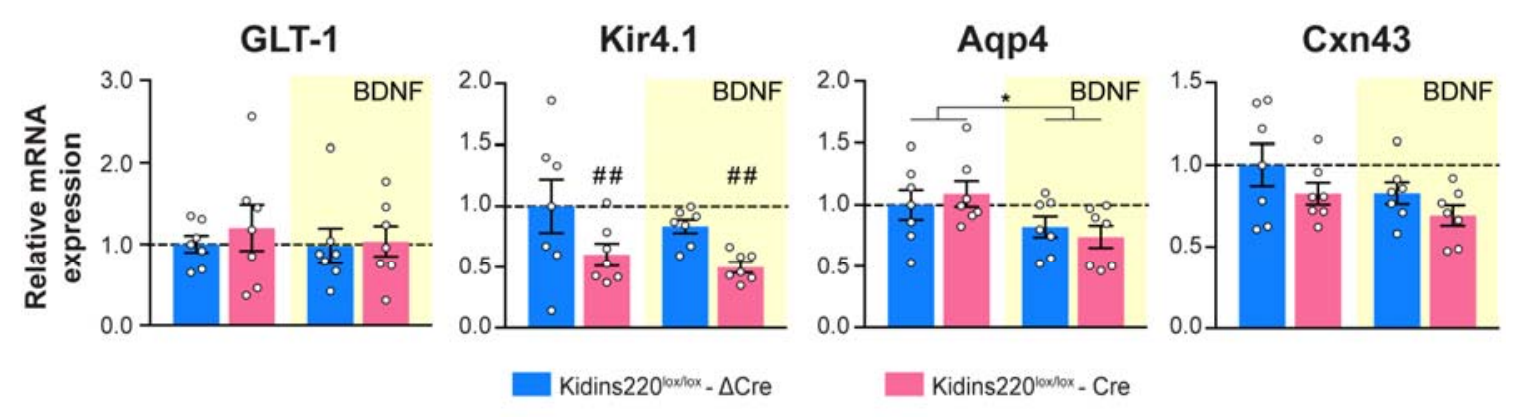

Figure 5

Figure 5. Transcription of Aqp4 and Kir4.1 in postnatal astrocytes are reduced by chronic BDNF and Kidins220 deficiency, respectively.

mRNA expression profile of glutamate transporter 1 (GLT-1), inwardly rectifying potassium channel 4.1 (Kir4.1), aquaporin 4 (Aqp4) and connexin 43 (Cnx43) in postnatal Kidins220 $0^{\text {lox/lox- } \Delta \mathrm{Cre}}$ and Kidins $220^{\text {lox/lox-Cre }}$ astrocytes with or without chronic BDNF treatment $(1 \mathrm{ng} / \mathrm{ml}$ for $72 \mathrm{~h}$, see Materials and Methods). mRNA expression in the various samples was normalized to the values of untreated 
Kidins $220^{\text {lox/lox- } \Delta \text { Cre }}$ samples within the same RT-qPCR plate. Two-way ANOVA followed by Tukey's multiple comparison test. ${ }^{*} \mathrm{p}<0.05$ versus untreated, \#\#p<0.01 versus Kidins220${ }^{\text {lox/lox- } \Delta \text { Cre }}$. GLT-1: Genotype effect: $F_{(1,24)}=0.3813, p=0.5427$; BDNF treatment effect: $F_{(1,24)}=0.2042, p=0.6554$; treatment $x$ genotype interaction: $F_{(1,24)}=0.1262, p=0.7255$. Kir4.1: Genotype effect: $F_{(1,24)}=8.817$, $\mathrm{p}=0.0067$ (\#\#); BDNF treatment effect: $\mathrm{F}_{(1,24)}=1.179, \mathrm{p}=0.2883$; treatment $\mathrm{x}$ genotype interaction: $\mathrm{F}_{(1,24)}=0.06038, \mathrm{p}=0.8080$. Aqp4: Genotype effect: $\mathrm{F}_{(1,24)}=0.002003, \mathrm{p}=0.9647$; BDNF treatment effect: $F_{(1,24)}=6.817, p=0.0153(*)$; treatment $x$ genotype interaction: $F_{(1,24)}=0.7202, p=0.4045$. Cnx43: Genotype effect: $F_{(1,24)}=3.302, p=0.0817$; BDNF treatment effect: $F_{(1,24)}=3.183, p=0.0870$; treatment $x$ genotype interaction: $\mathrm{F}_{(1,24)}=0.04637, \mathrm{p}=0.8313 . \mathrm{n}=7$ independent Kidins $220^{\text {lox/lox }}$ cultures. Values are expressed as mean \pm S.E.M. in all panels. 


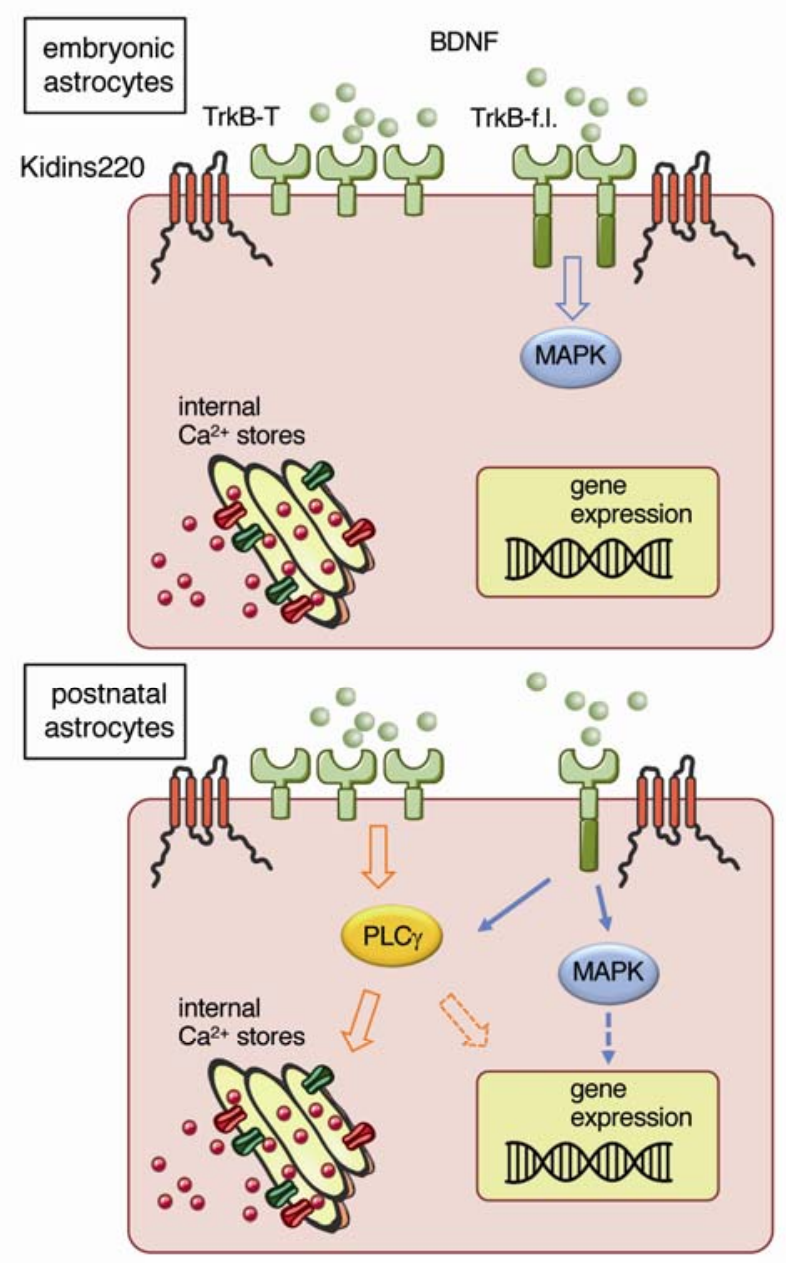

\section{Figure 6}

\section{Figure 6. Kidins220 differentially contributes to BDNF signaling in astrocytes.}

We propose a model whereby embryonic astrocytes (top) mostly respond to BDNF stimuli through full-length TrkB-dependent activation of intracellular signaling cascades, while in postnatal cells (bottom) BDNF mainly activates intracellular $\left[\mathrm{Ca}^{2+}\right]_{\mathrm{i}}$ transients via PLC $\gamma$. Kidins 220 contributes to the sustained activation of the MAPK pathway in embryonic cells, whereas it modulates Kidins220 BDNF-induced $\left[\mathrm{Ca}^{2+}\right]_{\mathrm{i}}$ transients in postnatal cells. Moreover, chronic BDNF treatment promotes the transcription of selected genes, such as Aqp4, in postnatal cells. 